\title{
Análisis del discurso de la prensa sobre las encuestas electorales en las elecciones generales de 1996
}

\author{
ALEJANDRO ALMAZÁN LloRENTE \\ CARMEN VILLAREJO RAMIREZ
}

\section{PRENSA Y SONDEOS ELECTORALES}

El contraste de los datos de las encuestas preelectorales publicadas con los resultados electorales inmediatos, intensifica un debate que antes se había mantenido en estado latente. A partir de la comparación, que pone en evidencia diferencias substanciales entre el pronóstico y los votos efectivos, se hacen más explícitas tanto las referencias a los métodos y las técnicas utilizados en la confección de sondeos y predicciones electorales, como los recelos y el escepticismo de algunos de los actores. Se debate sobre la cientificidad de las predicciones, los aspectos éticos de la publicación y la profesionalidad de periodistas e investigadores. Se habla de la intencionalidad de las publicaciones y de su influencia en los resultados. Se produce una ruptura en el consenso acerca de la encuesta como objeto científico y surgen dudas sobre su validez. Las figuras retóricas y las categorías empleadas en el discurso permiten analizar la organización del universo simbólico alrededor de los sondeos, y apreciar las diferencias en los discursos antes y después de la comparación de las predicciones y los resultados.

Antes de proceder al análisis de la polémica sobre las predicciones basadas en sondeos y su publicación en la prensa -tanto de los sondeos como del posterior debate acerca de su «fracaso»- es necesario detenerse en el contexto en el que se producen, atendiendo, no solamente al contexto político de las elecciones concretas, sino también a los antecedentes de este episodio del debate y el lugar de los sondeos y los medios de comunicación en el sistema político. 


\section{EL CONTEXTO}

\subsection{Los sondeos como parte del sistema político}

Para los partidos políticos los sondeos son un instrumento imprescindible. Encargan sondeos para diseñar, tanto la campaña como las estrategias a seguir en cada etapa del proceso electoral. Algunos politólogos consideran la encuesta como el único instrumento fidedigno para conocer la intención de voto (Cotarelo, 1996). No concebirían la organización de una campaña electoral sin la ayuda de los sondeos. En las elecciones del 96, como en anteriores procesos electorales, los respectivos portavoces de los grandes partidos -PSOE y PP- anuncian, mucho antes de la convocatoria de elecciones, que poseen sus propias encuestas sobre intención de voto. Al hacer afirmaciones sobre la situación política, se quiere dejar claro que no son afirmaciones subjetivas ni gratuitas, sino basadas en datos de encuestas. La encuesta tiene la utilidad inmediata de la predicción pero, cuando cumplen el objetivo de avalar afirmaciones, tienen también el valor añadido del dato objetivo que autoriza el discurso político.

La relación entre los sondeos electorales y la política se da también en otro sentido. Las empresas de investigación y los medios de comunicación coinciden en que las encuestas contribuyen a aumentar la cantidad de información del electorado, con la consiguiente mejora de las condiciones democráticas del proceso y la capacidad de discernimiento del votante. Con frecuencia se admite que la publicación de los sondeos puede influir en la emisión posterior del voto, pero sin que pueda precisarse el sentido de esa influencia. $¿$ adherirse al ganador o apoyar al perdedor? (Aedemo-Esomar, 1989). No obstante tanto las pretensiones de mayor libertad en el ejercicio del voto mediante la difusión de la información de los sondeos, como la prohibición de publicarlos durante los cinco últimos días, confirman el arraigo de la idea de la influencia. En un caso se cree que el ejercicio del voto puede ser mejorado gracias a la información proporcionada por los sondeos y en el otro, que hay que evitar que el voto sea influido por la publicación de los resultados de esos mismos sondeos. En estas dos posiciones subyacen modelos políticos diferentes. La difusión de sondeos pretende conferir calidad democrática al voto por acumulación de estímulos, aunque las características del mensaje de los medios de comunicación (la búsqueda del impacto periodístico, la estructura jerárquica de las proposiciones en las noticias y la construcción de titulares) pone más énfasis en la competición, la formación de mayorías y las estrategias de voto útil. Por el contrario, la posición de la ley que prohibe la publicación de sondeos en los últimos días de la campaña, pretende proteger la libertad del voto precisamente evitando la influencia de la publicación de sondeos, poniendo más énfasis en la reflexión personal. Si el primer modelo sugiere la calidad del voto por objetivación del entorno político, el segundo sugiere un voto personal creando un espacio para la identificación subjetiva del votante y el contenido político.

La frecuente publicación de resultados de sondeos y barómetros en los medios de comunicación de masas, hacen de los sondeos un objeto integrado en la cultura política del electorado. Los sondeos representan la objetivación de la 
opinión pública. No se trata ya de la voz pública depositada en los líderes políticos a través de los mecanismos democráticos de la representación en asociaciones e instituciones, sino de una medición por métodos científicos de esa opinión. La opinión no es expresada, sino producida técnicamente y con ello adquiere la credibilidad de lo científico. Como contrapartida, la opinión pública construida como suma de opiniones individuales, está privada de sus características conflictivas, de los intereses de clase y de su contexto natural. Aparece como opinión codificada, una medición realizada en un momento dado. La opinión objetivada, queda conformada por el propio modelo de medición.

Los sondeos electorales no sólo son profusamente utilizados, sino que además gozan de prestigio. Las ideas de ciudadanos que contestan libre e individualmente y la de representatividad democrática connotada a partir de la estadística, hacen de las encuestas políticas un instrumento «democratizado». Hay que tener en cuenta que la técnica de las encuestas se presta especialmente bien al campo de las consultas electorales, por el isomorfismo entre la adscripción a una lista de candidatos y a un item de una pregunta cerrada de cuestionario.

\subsection{Sondeos, opinión pública y medios de comunicación}

Desde que la opinión pública es entendida como criterio de legitimación en los regímenes de opinión surgidos del liberalismo del XIX, la publicidad de lo político se convierte en una pieza indispensable del engranaje electoral y un elemento clave del funcionamiento del sistema político. Actualmente, las encuestas electorales y de opinión (aplicadas a la política por primera vez en los años treinta), y su publicación en los medios de comunicación se han convertido progresivamente en la principal herramienta de construcción de esa «opinión pública». Las modificaciones en el modo en que se construye esa opinión tendrá repercusiones políticas importantes. En el estudio realizado por la Asociación Internacional de Sociología en 1981 Sobre Comunicación y Producción de la realidad, se constata:

«la inexistencia de cualquier forma de realización del modelo clásico de opinión pública, entendiendo por tal la existencia de valoraciones y decisiones, compartidas por los miembros de una comunidad, como resultado de un debate público y racional en el que todos participen, a propósito de los temas y problemas que les afectan en común. Y su sustitución por opiniones coyunturales de públicos de encuestas, realizadas mediante cuestionarios de preguntas cerradas y cuya formulación induce siempre, aunque en mayor o menor grado según los casos, la respuesta. No se trata pues de opinión pública sino de opinión del público o mejor de opiniones de públicos.» (Vidal Beneyto,1986).

Los sondeos se van integrando a la lucha política, como instrumento de predicción para los partidos, pero también -vía publicación en los medios de comunicación- como expresión objetiva de la «opinión pública». Desde los años sesenta los medios de comunicación asumen cada vez más el papel de mediación simbólica, no 
solo en la cultura, sino también en la política. Por otra parte los partidos de masas recurren cada vez más a los medios de comunicación como canales privilegiados de comunicación con los electores. (Grossi, 1985). Así, la actual crisis de los partidos de masas queda compensada por la capacidad de mediación simbólica y estructuración del ambiente político llevada a cabo por los medios de comunicación.

Los medios de comunicación utilizan los sondeos, también como medio de intervenir en la política. La relación privilegiada de la prensa diaria con la vida política se hace especialmente visible durante los procesos electorales. En el caso de los sondeos preelectorales, no se trata solo del lugar preferente que ocupan en el contenido de la prensa, sino también de los efectos reflexivos que produce su publicación en la vida política. En la medida en que los políticos trabajan en modificar la situación descrita en los sondeos, estos son rápidamente integrados en la lucha política. De alguna manera a través de los medios de comunicación se ejerce el poder, al imponer determinada definición de la situación, ante la que los políticos deben reaccionar. La prensa, mediante las encuestas de opinión -y más concretamente los sondeos políticos- adquiere el rango de actor político en tanto portavoz de la opinión. Pero con un lenguaje diferente al político y específico del medio.

En el caso que nos ocupa, las tradicionales rivalidades entre los medios de comunicación y las diferencias en sus inclinaciones políticas quedan reflejadas en la publicación de los sondeos. Abundan los artículos que denotan esa rivalidad. Los comentarios sobre la mayor credibilidad de los datos del sondeo encargado por el propio medio, siembran la duda sobre los de sus rivales o los que no coinciden con sus datos. Como ilustración, valgan los comentarios que desde las páginas de El Mundo ponen en duda los pronósticos electorales publicados por La Vanguardia (El Mundo, 26-2-96), asociando el pronóstico mas favorable al PSOE, a su afinidad por ese partido. Por su parte en un editorial de la Vanguardia después de conocerse los resultados, califica de periodistas sabelotodo de Madrid, a quienes ponían en duda su publicación (La Vanguardia, 4-3-96). Paralelamente a la confrontación política y la participación de los medios en la misma, se está produciendo otra entre los propios medios de comunicación, explicitando sus posturas respecto a los partidos políticos.

El protagonismo de las encuestas en los medios de comunicación en marzo del 96, vuelve a ser tan importante como en las anteriores elecciones generales de 1993. La contratación y publicación colectivas por parte de El Mundo, Antena 3 y La Cope, a Sigma 2 y Vox Pública, constituye una colaboración multimedia que promete ser algo más que circunstancial -por la forma en que es presentada en las páginas del diario-, convirtiéndose en algunos casos en el tema principal de la noticia (El Mundo, 27-2-96). Se está asistiendo a la pugna entre grandes grupos de control de medios de comunicación y su papel en la nueva situación esperada tras las elecciones.

\subsection{Contexto normativo y deontológico}

El Código Internacional de prácticas en materia de publicación de sondeos de opinión y las guías editadas sobre la materia para profesionales de los medios 
de comunicación por ESOMAR (European Society for Opinion and Marketing Research Association), sirven como punto de referencia para situar las prácticas concretas de publicación, así como para conocer la postura oficial de los investigadores en materia de sondeos. Las declaraciones de intenciones hacen referencia concreta a las directrices sobre las prácticas de sondeos electorales, y destacan la importancia de proteger, tanto los intereses del votante en una democracia como la reputación de la investigación social y de mercados (AEDEMO-ESOMAR, 1993).

La única referencia, en las publicaciones que nos ocupan, al marco legal en la publicación de los resultados electorales, se limita a la polémica sobre la pertinencia de las limitaciones (establecidas el la Ley Electoral) a la publicación de sondeos preelectorales en los cinco últimos días previos a la votación. Esta misma polémica, se desarrolla en términos similares en otros países europeos con las mismas limitaciones normativas.

Sólo la publicación en el diario $A B C$ (14-2-96) de una macroencuesta del CIS -que result 6 ser falsa-, provocó los comentarios de investigadores, periodistas e instituciones en los demás diarios. En este caso, además de la legislación electoral española, se desatendió la normativa del Código Internacional de Prácticas en Materia de Publicación de Sondeos de Opinión, que en su artículo 13, establece la prohibición de presentar como estudio las actividades que no lo son (AEDEMO-ESOMAR, 1986).

\subsection{Fiabilidad de los sondeos}

En las anteriores elecciones generales del 6 de junio de 1993, ya se hablo del singular protagonismo de los sondeos electorales durante la campaña. Las predicciones fallaron y se entablo una discusión sobre la fiabilidad e incluso la validez de las encuestas y predicciones electorales. El debate en torno a las encuestas preelectorales de las elecciones del 3 de marzo del 96, deben entenderse como una continuación del anterior debate sobre los fallos en los pron6sticos de las generales del 93 o las catalanas del 95.

En 1996 un breve manifiesto «AEDEMO ante el próximo proceso electoral», transmite la posición del sector frente a las elecciones convocadas para el 3 de marzo. Tras expresar inquietud por la imagen desfigurada que la sociedad pueda percibir de su trabajo y sus resultados, se recuerda que los resultados están sujetos tanto a factores de indeterminación estadística, como dinámicos de la situación política. Por último se invita a utilizar las precisiones estadísticas y los detalles de la realización de las encuestas para relativizar la información y situarla en su adecuado contexto. Se pide explícitamente a partidos y medios de comunicación, respeto hacia el trabajo de los profesionales y «sensibilidad ante sus limites intrínsecos y circunstanciales».

Periodistas, políticos y responsables de las empresas de investigación manifiestan actitudes diferentes ante los sondeos electorales. En la guía de interpretación y publicación de resultados de encuesta, dirigida a los profesionales de los medios de comunicación y editada por AEDEMO-ESOMAR en 1989, refirién- 
dose a los sondeos electorales ya se advertía: »los prejuicios sobre las encuestas y los investigadores existen entre los periodistas, y lo mismo es verdad al revés». Se argumenta que si los periodistas (como el público) tienen la impresión de que los sondeos con pretensiones de pronóstico se equivocan la mayor parte de las veces, los investigadores pueden creer que los periodistas siempre tergiversan los resultados. En otra publicación de ESOMAR sobre los sondeos se expresa una queja: «las encuestas se equivocaron es una noticia y alcanzará una gran cobertura en los medios. Las encuestas acertaron es un titular que jamás se escribirá» (Esomar Aedemo, 1993).

Las diferencias entre ambos colectivos permanecen latentes durante el período de contratación y publicación de los sondeos preelectorales, pero se manifiestan con fuerza tras la comparación de los pronósticos con los resultados.

\subsection{Otra tregua en el debate sobre la credibilidad-fiabilidad de los sondeos}

El inicio de un nuevo proceso electoral viene acompañado de un olvido temporal del problema de la credibilidad-fiabilidad de los sondeos. Si bien determinados articulistas en algún momento relativizan el valor de las predicciones, en los titulares de las páginas adyacentes se extraen conclusiones y se realizan afirmaciones categóricas, avaladas por las mismas predicciones. En todo caso las condiciones de verosimilitud de las proposiciones afirmativas tienen un rango inferior en la estructura semántica de la noticia que la afirmación misma.

A la hora de publicar los resultados de las encuestas y las predicciones, no se ponen en duda los aspectos técnicos y científicos, se actúa como si el modelo no planteara problema alguno. La «caja negra» está cerrada, y la credibilidad de sus producciones tácitamente consensuada. La inserción del proceso de producción de la opinión pública en el mercado de los medios de comunicación («Más de 500 millones en encuestas», La Vanguardia, 4-3-96), puede estar en el origen de la tregua.

\subsection{Contexto político inmediato}

Todos los medios coincidían en calificar el clima político que desembocó en la convocatoria de elecciones anticipadas para el 3 de marzo, como de gran crispación, que la convocatoria de elecciones contribuiría en gran parte a normalizar. El ascenso del PP en las elecciones precedentes y los procesos judiciales por corrupción abiertos a miembros del partido en el gobierno aumentaban la expectación sobre el proceso electoral de marzo de 1996. La posibilidad de aternancia del partido en el poder, por primera vez en más de una década, estaba presente en las estrategias electorales de los diferentes partidos. La vida política española se caracterizaba por una tensión, cambio y fluidez inusuales. Los cambios en el clima político habían sido ya señalados como una de las causas principales del «fracaso» de los sondeos en anteriores procesos electorales (Wert, 1995). 


\section{LA PUBLICACIÓN DE SONDEOS EN LA PRENSA}

Seleccionemos cuatro diarios de gran difusión: $A B C$, El Mundo, El País y La Vanguardia. Si bien la representación de los diarios no es exhaustiva, incluye cuatro de los diarios de mayor difusión y protagonismo en la vida social española. Se trata de los periódicos cuyas publicaciones de sondeos tienen más reflejo en las referencias cruzadas de la propia prensa (cuando los periódicos mencionan las encuestas publicadas por los demás), aunque ocasionalmente se mencionen los sondeos publicados por El Correo de Andalucía y el Periódico de Cataluña. Las diferencias entre los diarios seleccionados, puede servir para contrastar los estilos periodísticos y los discursos al tratar de un mismo objeto.

El período 1-1-96/15-3-96 recoge todos los sondeos realizados específicamente para los diarios seleccionados, así como abundantes referencias a otros sondeos encargados por partidos, instituciones, y otros medios de comunicación, así como diversos artículos, noticias y editoriales referidos más o menos directamente a los sondeos.

En los sondeos publicados por estos cuatro medios de comunicación, puede apreciarse el agrupamiento de la publicación en unas pocas fechas. Llama la atención, sin embargo, el intervalo de tiempo transcurrido entre el trabajo de campo y la publicación en el caso de $A B C$ (encuesta de «urgencia» de Tabula $\mathrm{V}$ para $A B C$, publicado el 21-2-96).

También son dignas de reseñar las diferencias en los tamaños de las muestras, desde la pequeña muestra de 1.000 unidades con preguntas realizadas por teléfono, a las macroencuestas con muestra de 12.000 unidades y entrevistas directas.

\section{CARACTERÍSTICAS GENERALES DE LA PUBLICACIÓN DE LOS SONDEOS}

El discurso de la noticia es un discurso público. Para que la noticia sobre un tema sea inteligible, requiere que exista un universo simbólico compartido (Van Dijk, 1990). En ese sentido el estilo periodístico puede servir para informar sobre la configuración de las representaciones y las diferencias entre los diferentes discursos. Las imágenes proyectadas de los sondeos y su realización, y las metáforas, a veces tópicas de la retórica de la noticia, están presentes en los cuatro diarios consultados y son en gran medida compartidas. Si bien las diferencias de estilo pueden discriminar los discursos de los diferentes diarios, las coincidencias darán cuenta de la base común. Del universo simbólico en que se funda la posibilidad de comunicación del objeto.

No se trata de buscar la objetividad de los contenidos de las noticias y artículos. Desde los años setenta se asiste al fin del dogma de la objetividad como modelo de conducta periodística. Se reconoce la imposibilidad de reproducir informativamente la realidad, tal y como es, de forma literal y unívoca. En su lugar la objetividad queda entendida como el control objetivado de la propia subjetividad (Vidal Beneyto, 1986). Lo que se pretende es conocer el imaginario compartido sobre el objeto a partir de su manifestación periodística. 


\subsection{Imágenes transmitidas sobre la autoría de los sondeos}

La mención de la autoría del sondeo puede cumplir objetivos diferentes ( $y$ en cierto modo opuestos) dependiendo de la forma que adopte. Una primera forma es la que confiere credibilidad a la información: la autoría es mencionada como garantía de veracidad. La empresa que realiza la investigación, es una referencia obligada por las normas mínimas de publicación de sondeos. En principio, la mención de la empresa confiere prestigio y autoridad a las afirmaciones que siguen y apariencia de verdad a los datos que acompaña. Establecer una fuente solvente para los datos publicados, supone garantía de verdad. El peso de la profesionalidad de los actores y cientificidad de los métodos y técnicas, avalan los comentarios y las consecuencias publicadas acerca de los datos. El prestigio de las empresas aparece como veracidad connotada en las proposiciones de la noticia.

Una segunda forma de utilizar la autoría consiste en relativizar o poner en duda la información. La existencia y el carácter del objeto varía en función de los diferentes entramados sociales (Woolgar, 1991). Las referencias sobre la autoría pueden actuar como modalizadores de un enunciado, cuya factilidad puede incrementarse $o$ rebajarse mediante la inclusión o exclusión del agente, la acción del agente y las circunstancias o intereses del mismo. El enunciado: «PARTIDO OBTIENE \% DE INTENCIÓN DE VOTO», es modificado por «SEGÚN UN SONDEO DE LA EMPRESA TAL», o por la frase "SEGÚN HIPOTESIS DE DISTRIBUCIÓN DE INDECISOS». Las referencias a la acción del agente relativizan la primera afirmación. Mientras que la omisión del agente y sus acciones tienden a objetivizar el sondeo, las menciones de las personas y procedimientos concretos los relativizan.

También, en determinados casos, los periódicos asumen cierto protagonismo en la autoría del sondeo, en su propio beneficio. La clásica y lacónica referencia «...según un sondeo de EMPRESA para PERIÓDICO...», se torna «el sondeo de $L a$ Vanguardia» en un editorial, tras las elecciones, cuando resultó ser «el que más se acercó al resultado». Por motivos diferentes, el diario El Mundo recoge en forma de noticias, la contratación y publicación de los sondeos que encarga, junto con La Cope y Antena 3, a las empresas Sigma 2 y Vox Pública, con el propósito de «ampliar el impacto del sondeo mediante la publicación multimedia». Se hace explícita una postura activa en el terreno político y de la opinión pública (El Mundo, 29-1-96).

En contraste con esa imagen, después de conocerse las diferencias entre pronósticos y resultados, se produce una clara separación entre empresas de investigación y medios de comunicación. Al mismo tiempo, aparecen en los medios de comunicación los responsables de las empresas de investigación como actores principales, haciéndose explícita su intervención como sujetos, hasta ese momento omitida. La intervención de la subjetividad del investigador sirve para apoyar la crítica del objeto.

\subsection{La representación científica de la intención de voto}

En el proceso de construcción de la representación de la intención de voto, al igual que en otros procesos técnicos y científicos, se atribuye una intervención míni- 
ma al sujeto (investigadores y entrevistados). El modelo ideal que subyace es el de un instrumento de medición (encuesta), que nos revela algo que está ahí (opiniónintención de voto). Se espera del investigador que asuma un papel neutro para no afectar a la realidad observada. La aceptación de la representación, dependerá por tanto de la plausibilidad de la tecnología y el método empleados. Si bien en otro lugar se argumenta que la realidad puede cambiar y la representación ya no serviría o no sería todo lo fiel que se espera de ella, en la publicación de los sondeos se insiste en las afirmaciones categóricas: «si las elecciones se celebrasen hoy...». Prevalece la imagen del sondeo como expresión objetiva de la opinión o la intención del voto.

Por más que la elaboración de pronósticos sobre la intención de voto requiera de la acción subjetiva del investigador -en acciones como asignar intención de voto a los indecisos-, prevalece la imagen connotada del agente neutro del que sólo se espera que realice una mediación correcta entre el objeto y la representación.

\subsection{La retórica de la factualidad}

Uno de los apoyos más explícitos del ejercicio de la persuasión periodística reside en acompañar la información con dimensiones emocionales, emociones fuertes que se representan y memorizan mejor. Menos visible, pero siempre presente en la publicación de sondeos, es el hecho de acentuar la naturaleza factual de los acontecimientos. Las predicciones y aún las posibles consecuencias que se derivarían de su cumplimiento, están referidas en tiempo presente y son presentados como hechos. La retórica de la noticia incide sobre las condiciones que subrayan la naturaleza factual de los hechos (Van Dijk, 1990).

Una idea recurrente es la de presentar la opinión pública o la intención de voto como algo cambiante que está ahí, y de lo que se pueden conseguir fotografías instantáneas en sucesivos momentos. Las metáforas gráficas como la instantánea, el dibujo del mapa político, la panorámica ofrecida, etc, connotan la virtualidad y actualidad del sondeo. Se recurre con mucha frecuencia al esquema: PREDICCIÓN + CONDICIÓN ( $\ll$ si se celebrasen hoy las elecciones») $\Rightarrow$ REALIDAD FACTUAL (consecuencias). El hecho de representar el factor temporal como única condición, añade virtualidad y actualidad a la proposición primera. La connotación introducida mediante la metáfora no pasa por el filtro de la razón, y ahí reside su efectividad, colaborando en transmitir la idea de algo que está ocurriendo, y el periodista que elabora la noticia está presenciando.

El esfuerzo retórico por transmitir virtualidad a las afirmaciones acerca del sondeo llega en algunas ocasiones hasta el extremo de referirse a la intención de voto como «votos válidos» (El Mundo, 30-1-96) o incluso como «votos emitidos» (El País, 11-2-96).

\subsection{La reificación de los sondeos}

En el proceso de construir proposiciones con la mayor apariencia de verdad o plausibilidad, se tratan de objetivar las afirmaciones. En este sentido, el sondeo 
representa la objetividad, y su reificación el máximo grado. En las publicaciones el sondeo (como ocurre con otros productos del conocimiento humano) es aprehendido como si no fuera humano, como una fuerza autónoma de la naturaleza. El producto objetivado pierde su comprehensibilidad como empresa humana y aparece como factualidad autónoma. Es especialmente plástica la metáfora que aparece en la noticia de El País sobre un mitin de Felipe González en La Coruña, que califica las predicciones de resultados electorales del PSOE, como mal tiempo demoscópico, connotando el aspecto de fuerza natural.

Los sondeos actúan por sí mismos. Bajo la forma de metáforas del verbo los sondeos dibujan panoramas políticos, otorgan intenciones de voto, muestran estados de opinión, perfilan composiciones de parlamento, o señalan tendencias (si bien podría establecerse una tipología que diferencie los diversos diarios, según la utilización de estas metáforas, existen muchas similitudes entre ellos). Todo elemento de subjetividad inherente a la producción social de la opinión y las predicciones, queda eclipsada. por la preexistencia del objeto antes de la observación. $\mathcal{L}^{1}$ fenómeno de la reificación aparece especialmente claro en la machacona afirmación del discurso de Felipe González durante la campaña: «vamos a ganar a las encuestas». Las encuestas y no el PP, representan el rival político.

Antes de producirse los problemas, mientras la caja negra funciona, no se mencionan a las personas quc realizan la predicción. Se dice: «...según el sondeo...». Habrá que esperar a la publicación en $A B C$ de un sondeo inexistente del CIS, o al importante contraste entre los pronósticos y los resultados, para oír la voz de los técnicos y directores de las empresas e instituciones que realizaron las encuestas.

\subsection{La retórica del número}

El número, como simplificación fácil de memorizar y transmitir reúne óptimas condiciones para servir de vehículo al contenido de las noticias. Con frecuencia es empleado para connotar apariencia de verdad, recubriendo las proposiciones con la ausencia de ambigüedad que caracteriza a las cifras exactas (Van Dijk, 1993). Cuando en el titular de la noticia se resalta una diferencia de tres décimas entre el sondeo de una semana y la siguiente, lo verdaderamente importante no es la magnitud de la diferencia (con más de un $20 \%$ de indecisos), sino la sugerencia de verosimilitud asociada a la cifra y sus decimales. Al mismo tiempo, la cantidad, en tanto que medida sugiere la presencia real del objeto medido.

El tamaño de la muestra y el margen de error estadístico, en el caso de las macroencuestas publicadas por El Mundo, salen del reducto de la ficha técnica, para ocupar la categoría de tema para una noticia desempeñando el mismo papel que el porcentaje con decimales en la intención de voto.

\subsection{El proceso electoral como carrera}

El macrosondeo publicado en $E l$ Mundo es presentado en sus titulares como verdadero "pistoletazo de salida» del 3-M (El Mundo, 29-1-96). La exclusión de 
sentido producida por la inclusión del pistoletazo en la frase sobre el tema sondeos y elecciones, remite al contexto del atletismo, y la distancia que hay que recorrer hasta ese otro contexto donde tiene coherencia, la convierte en una metáfora fuerte. El proceso electoral representado aparece connotado como espectáculo. El titular «El PP asienta su ventaja» y las frases «los socialistas recuperan posiciones»o «el PP aumenta su ventaja poco a poco sobre el PSOE» tienen un significado condicionado por el título de la inserción: «La carrera electoral», seduciendo con la emoción y la acción propios de los acontecimientos deportivos (El Mundo, 12-2-96). En la portada de El País, la forma de referirse a las «ventajas» de unos partidos sobre otros y la connotación de movimiento que sugiere el seguimiento de las «tendencias» observadas al comparar sucesivos sondeos, se prestan también a la metáfora deportiva, aunque de forma más velada. El pronóstico sobre el ganador, o la representación de la ventaja en seguimiento periódico, son más aptas para su presentación como espectáculo que la publicación de los contenidos de los programas de los partidos o los argumentos políticos concretos. Las características del medio y su lenguaje específico, contribuyen a definir el objeto. La exaltación de la competencia y la simplificación de los contenidos a fórmulas fácilmente transmitibles, contribuyen a configurar una percepción de la política muy específica : reducida a su aspecto formal. Pero la construcción de metáfora deportiva puede ser anterior al momento de la publicación: en el artículo que comenta el proceso de obtención de las predicciones, se describe el voto a «caballo ganador», como una de las categorías empleadas para la estimación del valor más probable de distribución de escaños $(A B C, 25-2-96)$. En cualquier caso, la metáfora deportiva consigue transferir la energía afectiva evocada por la imagen asociada al campo político, pero al mismo tiempo transmite una visión del proceso electoral reducido a sus aspectos mas dramáticos.

Las metáforas expresan juicios de valor porque la imagen asociada que introducen provoca una reacción afectiva, teniendo por función expresar un sentimiento que intenta sea compartido (esta es la más importante de las motivaciones de la metáfora). En términos de las funciones del lenguaje de Jakobson, la función metalinguística centrada en el código hace posible la metáfora pero encontrará sus motivaciones esenciales en las funciones conativa y emotiva, centradas en la orientación hacia el destinatario y el remitente (Le Guern, 1990).

\section{LAS CARACTERÍSTICAS ESPECÍFICAS DE LA REPRESENTACIÓN DE LOS SONDEOS EN DIFERENTES PERIÓDICOS}

\subsection{El caso del $A B C$}

La publicación de sondeos en el $A B C$, está marcada por el episodio de la publicación, el 14 de febrero, de unos datos y predicciones como macroencuesta del CIS «encargada por el gobierno» y que resultaría ser falsa.. Los demás perí6dicos publicarán diversas noticias acerca de las consiguientes protesta y denuncia ante la Junta Electoral, los recursos presentados y la desatención a los requerimientos de rectificación de la noticia. 
Antes de este suceso, las noticias sobre encuestas preelectorales y pronósticos, se refieren a los barómetros del CIS y las mencionadas por los políticos en sus declaraciones electorales. A diferencia de otros períbdicos el $A B C$ no publica un sondeo contratado por el propio diario hasta el 11 de febrero. En los titulares se anuncia un sondeo en exclusiva para $A B C$, pero en la ficha técnica figura: basado en varias encuestas exclusivas para $A B C$. No se mencionan las empresas que realizan la investigación ni el número de encuestas de que se trata, aunque paradójicamente se especifica el número de entrevistas y el error de muestreo.

El 21 de febrero aparecerá publicada una «encuesta de urgencia» realizada por Tabula V para $A B C$. En este caso la ficha técnica esta cumplimentada convencionalmente, aunque llama la atención el período transcurrido entre la realización del trabajo de campo 23/26 enero y la publicación 21 febrero, teniendo en cuenta que los otros diarios reducen ese período al mínimo para aprovechar la actualidad de los datos, en el supuesto de que los datos reflejan la situación de un momento preciso. Cuatro días después $A B C$ publicará otro sondeo realizado por Tabula V, y aunque la diferencia de tiempo entre el trabajo de campo y la publicación es menor, sigue superando con mucho al de las otras publicaciones observadas. En todo caso el $A B C$ publica muchas menos noticias e informaciones acerca de los sondeos preelectorales que los demás diarios.

\subsection{El País}

Las referencias a El País como «especie de representante formal de la opinión pública» o como "guardián casi exclusivo del espíritu democrático» (Imbert, 1986), nos hacen retroceder al período de la transición democrática española. Pero la situación política y el mundo de los medios de comunicación ya no son los mismos. Aunque como periódico de prestigio sigue desempeñando un importante papel en la construcción de la realidad social y la defensa de las instituciones.

La forma de citar sondeos en abstracto, varía mucho según su procedencia. Para hablar de los realizados por el PP, se escribe: «Rajoy aludió a ciertos "estudios sociológicos", sin concretar ni su autoría ni su contenido, para expresar que existe un deseo generalizado..» (6-1-96), la forma de referirse a los pronósticos hace que parezcan dudosos. Sin embargo, cuando se habla de las declaraciones de González, «..había descubierto por los sondeos que le habian pasado desde su partido que los socialistas están cuatro décimas mejor situados ...» (7-1-96). Los sondeos quedan relativizados en virtud de la posición política de quien los utiliza como argumento.

A diferencia de los demás diarios, en los titulares de El País no se menciona al PSOE (excepto en el primer sondeo), Solo se cita la ventaja del PP, que aumenta y se consolida, se asegura que el PP ganará y que está al borde de la mayoría absoluta. Pero la referencia de la ventaja no es nombrada. En los dos días posteriores a la publicación del segundo sondeo de Demoscopia en El País, se dedican los titulares de las dos portadas, al anuncio de la inminente llegada al gobierno de los populares. Se puede leer: 
«El PP quiere anular la rebaja de penas nada más llegar al gobierno» (112-96), y «El PP dará a empresas privadas la auditoría de las cuentas del Estado» (13-2-96). Los mensajes se acompañan de: «González asegura que ganará a las encuestas».

La jerarquía de las proposiciones en una noticia, se organizan para resaltar qué es lo esencial y qué lo accesorio. El tema principal de la noticia queda resumido en el titular, pero será el conjunto de las proposiciones el que defina el tema (Van Dijk, 1993). En ese sentido es importante fijar la atención en el lugar que ocupan y su estructura lógica. En las publicaciones del primero y el último de los sondeos se pueden observar características diferentes en la estructura temática. Mientras que en el primer caso las afirmaciones quedan relativizadas por las condiciones:

afirmación - Titular: = El PP aventaja al PSOE en casi 7 puntos.

condición - Entradilla del titular: = El PP aventajaría si se celebrasen hoy las elecciones.

condición - Cabecera primer párrafo: = El PP obtendría el $40 \%$ de los votos, según la hipótesis de distribución del voto... (14-01-96).

en la publicación del último sondeo la estructura ha cambiado, las condiciones de la proposición principal, han sido atenuadas y relegadas a un plano inferior.

afirmación - Titular: $=$ El PP podrá gobernar en solitario con mayoría de 170 a 178 escaños.

afirmación reiteración - Entradilla del titular: = José M. ${ }^{\circledR}$ Aznar tiene prácticamente a su alcance la mayoría suficiente.

condición - al final del Texto = no obstante hay un 14\% de indecisos (25-02-96).

En el editorial de ese mismo día se transmite la misma idea de virtualidad del pronóstico: «todo parece decidido... ante la ausencia de incertidumbre... porque su victoria es casi segura...»

La postura global respecto a los sondeos electorales es la de dar crédito a los datos sin reservas. Ni el repetido anuncio de otros sondeos en poder del PSOE, y que difieren en el pronóstico, crean disonancia en la línea del diario. No se pone en duda la cientificidad de las encuestas ni su fiabilidad, pero tampoco se hará apología explícita de la exactitud.

Los datos técnicos no salen de la ficha técnica, y las referencias al tamaño de la muestra en el texto de las noticias, cumplen solo la función de justificar la estimación en número de escaños de los pronósticos, si el número de unidades de la muestra lo permite técnicamente.

\subsection{El Mundo}

Los sondeos merecen un tratamiento especial en este diario. Aparte de la publicación en forma de noticia de los sondeos encargados por el diario, se dedi- 
can muchos artículos a los sondeos en si mismos. Las macroencuestas realizadas por Sigma 2 y Vox Pública para El Mundo, Antena 3 y La COPE, son el contenido de al menos 9 inserciones entre el 26-1-96 y el 27-2-96. Son presentados como «aventura multimedia» en al que tres medios actúan «amplificando el impacto de la macroencuesta».

No solo se trata de poner de relieve las características del primer sondeo multimedia, y el gran impacto de su publicación simultánea. El tamaño de la muestra se convierte en titular de noticia, es decir, en el contenido principal que se desea resaltar. La referencia a las 11.000 unidades de la muestra, es explicada por sus consecuencias: «lo que supone un margen de error estadístico de solo el 1\%», se trata de un trabajo capaz de «aproximar al máximo la realidad» (22-1-96). Los editoriales no son una excepción, en el del día 28-1-96 se insiste:

«el retrato del mapa político...proporcionado por la macroencuesta... viene a confirmar, con la fiabilidad que adquiere un trabajo de campo de 11.000 entrevistas personales...»

Se pretende que los macrosondeos publicados en el diario, se han convertido en el punto de referencia de la campaña. La magnitud del trabajo de investigación y la gran difusión dada a los resultados, son el soporte de la legitimación del actor político -que designa la referencia a tener en cuenta-. Esta visión es coherente con afirmaciones hechas tras la publicación de un sondeo, cuando se dice que tal o cual partido, a la vista de los sondeos se aplica a «arañar votos».

Si en El País se omitía la referencia de la ventaja, en El Mundo, se enfatiza. «El PP aventaja al PSOE», «el PP se distancia aún más del PSOE», «se agranda la brecha entre el PP y el PSOE», «el PP sigue creciendo y aventaja ya en 10.9 puntos al PSOE». También hay abundantes referencias a los sondeos previos, se cuentan los decimales semana a semana, y se proyecta una idea de movimiento observado en distintos momentos:

«en dos semanas los conservadores han aumentado un $0,4 \%$ su intención de voto..» (11-2-96). «El partido popular ha aumentado en poco más de medio punto porcentual su ventaja respecto al PSOE... este incremento se ha producido en tan solo una semana» (14-1-96).

La estructura de las proposiciones en las noticias de sondeos sigue la secuencia:

Afirmación - titular: El PP aventaja en 9 puntos al PSOE

Consecuencia y condición - texto: lo que significa que si se celebrasen hoy las elecciones... (7-01-96).

Se diferencia claramente entre los datos del sondeo y los pronósticos que en base a los mismos pueden hacerse. La exactitud de los datos del sondeo no es puesta en duda (para los sondeos contratados por el propio periódico), se recurre con insistencia a la metáfora de la foto instantánea de un momento concreto. La fidelidad de la foto queda representada por la técnica y la precisión (tamaño muestra). La virtualidad sugerida por la condición «si se celebrasen hoy las 
elecciones», es usada con frecuencia, y confiere coherencia lógica a esta postura. El pronóstico sin embargo es relativizado en diversos lugares, en artículos y editoriales:

«ningún sondeo de opinión puede predecir con exactitud matemática lo que sucederá el 3-M... pero puede ser la fotografía mas exacta de un momento concreto...» (27-1-96) y «pero los sondeos -incluso cuando se basan en una muestra tan amplia como...- son reflejo de la situación existente en el momento de su realización. No pretenden ser profecías..» (25-2-96).

No se duda de la técnica empleada para pronosticar, sino de las circunstancias cambiantes y la indeterminación propia del proceso electoral, como la existencia de voto oculto.

Los sondeos que plantean alguna duda son los encargados por otros medios o partidos. Se ponen en duda los datos que maneja el PSOE y que anuncian una diferencia menor, y también se pone en duda el último sondeo de La Vanguardia. Desde las páginas de opinión, German Yanke critica a Alfredo Abian y José Antich por su falta de cautela al publicar los datos en base a motivos técnicos: «...uno no puede menos que confiar en que los sociólogos hayan distinguido entre el 33\% de esos indecisos, votantes anteriores del PSOE, el 23\% de votantes de Izquierda Unida y el resto». Se critica el «tono» del análisis de los datos.

La coincidencia de los datos de los sondeos es interpretada como indicador de fiabilidad:

«El resto de las encuestas publicadas ayer, y que no difieren en lo fundamental de la adelantada por El Mundo, indican en contra de La Vanguardia, que el PP...» (26-2-96) y «...sacando la media entre todas las encuestas publicadas, un $40.7 \%$ de intención de voto. Esta media coincide con los sondeos de El Mundo...» (8-2-96).

La idea de la media de muchas medidas de un solo objeto, lejos de querer representar el consenso, sugiere la verdad de los datos. Pero la postura global del diario frente a la cientificidad y la credibilidad en las encuestas, contrasta con la adoptada por el diario después de las elecciones.

\subsection{La Vanguardia}

En la publicación de los sondeos en este diario, se presenta un discurso más moderado en cuanto al sondeo como objeto científico. En la presentación de los sondeos como noticia, se emplean menos las afirmaciones categóricas, y aparecen más condiciones que las relativizan (sobre todo en la primera parte de la campaña electoral).

Afirmación condicionada - titular: El PP ganaría hoy con casi el $40 \%$ de los votos.

Condición - texto: aunque importante $n .^{\circ}$ de indecisos. 
condición - texto: el pronostico es incierto en cuanto a la magnitud de los resultados... (14-01-96).

Si bien en otras ocasiones la afirmación es especialmente rotunda expresando el pronóstico en tiempo presente, y estableciendo las consecuencias futuras del cumplimiento de la predicción:

\section{afirmación - titular: Aznar gana sin apabullar}

consecuencia - texto: discurso presidencial. ...palabras que serán dichas por Aznar el domingo a las 11 de la noche... (25-02-96).

La relatividad de las predicciones está diseminada por el texto mediante el uso de los verbos en forma condicional. Además, se nombra a menudo a los encuestados y sondeados, atribuyendo los porcentajes de intención de voto a éstos en vez de hacerlo a la totalidad de los electores.

Como en el caso de El Mundo, los editoriales y no la noticia directa constituyen el espacio donde se expresa la duda: «La suerte no está definitivamente echada» (25-2-96) y «Si nos fiamos de las encuestas, Aznar va por delante» (29-2-96).

Sin embargo, al contrario que en el caso de El Mundo, el contraste de los resultados con los pronósticos, reforzará la posición cientificista. La Vanguardia trata de marcar la diferencia entre el pronóstico del Instituto Opina para La Vanguardia, como trabajo profesional bien hecho «que más se acerca a los resultados», y el resto de los pronósticos publicados en los medios (4-3-96). Se ironiza sobre las grandes muestras utilizadas por otros investigadores con predicciones menos acertadas, en comparación con su modesto trabajo de 1.800 encuestas telefónicas: «La Vanguardia fue el único diario que, basándose en su propia encuesta, auguró un triunfo del PP muy ajustado» (5-3-96).

\section{EL NÚCLEO DURO DEL OBJETO}

El núcleo de los sondeos como significante que circula socialmente está configurado por dos de sus propiedades generalmente admitidas y que no son puestas en duda (salvo por algunos escépticos) en ningún momento: la condición de representación científica de una realidad preexistente y la democraticidad del procedimiento técnico. La preexistencia del objeto, y aún su presencia, que permite constantes mediciones en busca de tendencias y movimientos, es sugerida no solo por los titulares de los diarios sino por las empresas que realizan los sondeos. AEDEMO en la «Guía para los profesionales de los medios de comunicación acerca de la interpretación y publicación de los resultados de las encuestas», reconoce que las encuestas son un arte muy poco preciso, más un juego que una ciencia y advierte: «si nos gusta la precisión en los números puede que las encuestas no vayan a gustarnos demasiado». Pero podemos ver como en el mismo texto más adelante se estimula la contratación de encuestas más grandes 
en aras de la precisión: «...donde hay un resultado muy reñido... se necesitan muestras muy grandes para obtener buenos pronósticos». La realidad esta ahí, el problema es medirla y controlar los factores de indeterminación interna (estadística) y externa (política).

La representatividad democrática está connotada a partir de la representatividad estadística y produce una ficción de la democracia formal -no votan todos, el voto no es secreto y no tiene consecuencias políticas directas como la asignación efectiva de escaños.

La asociación de empresas de investigación, y los diarios, al criticar la prohibición de publicar sondeos en los últimos días del proceso electoral, apelan a la contribución a la calidad democrática que se obtiene mediante la información de los datos de sondeos. La posibilidad misma de que los diarios se conviertan en representantes de la opinión pública, o la de proporcionar información útil desde el punto de vista democrático, están fundadas en estas dos características nucleares de los sondeos.

La predicción tiene menos fuerza que los datos del sondeo en sí. Desde las publicaciones de AEDEMO, y desde las páginas de los periódicos, se relativiza el valor de las predicciones, aunque sin restar fuerza a las consecuencias que de su cumplimiento se derivaría. Se produce una situación contradictoria consistente en dar las predicciones como un hecho, resaltado por sus consecuencias inminentes y reales, aunque también se insiste en que los sondeos no son una profecía ni matemáticamente exactos. Este grado de indeterminación aparece recubierto de metáforas (también muy utilizadas en los cuatro diarios observados) magico-religiosas como augurio, profecía, oración, etc. El componente mágico hace que parezca que nos enfrentemos a una creencia recubierta de racionalizaciones.

Tras la creencia fiel en el modelo estadístico sobreviene la indignación por el Fracaso de sus predicciones, postura calificada por Alfonso Orti como «ingenuidad cientificista» que desatiende la naturaleza doblemente subjetiva de la producción de los pronósticos de los sondeos (Ortí, 1996).

La mayor parte de las explicaciones del fracaso hacen referencia a «la cocina»: la aplicación de índices de ponderación invariables desde hace años -a pesar de que la situación política es cambiante-; la falta de atención al indicador de popularidad de los líderes -que contradecía las intenciones de voto explicitadas-; la falta de rigor técnico, etc. Los datos en bruto del sondeo, son elaborados de forma artesanal. La predicción es más un arte que una técnica: «un arte muy poco preciso, más un juego que una técnica» (AEDEMO-ESOMAR, 1989). Desde el momento en que se pretende hacer una predicción, se hace necesaria la intervención del oficio y la destreza del personal investigador. En el debate, todas las críticas y justificaciones van dirigidas a la intervención subjetiva del investigador, antes oculta tras la exactitud y cientificidad de la medición -cuya objetividad eclipsaba la intervención humana-. Las manifestaciones de politólogos y técnicos van dirigidas en este sentido. El objeto está ahí, y el instrumento de medición funciona mientras las circunstancias de indeterminación externa al modelo permanezcan bajo control. Simplemente se asume la necesidad de efectuar algunos ajustes. No obstante los propósitos manifestados por los responsables de las 
empresas de investigación tras las elecciones de 1993, acerca de la «reformulación de los métodos de prospección» de resultados electorales, sigue siendo un trabajo pendiente. Vuelven a argumentarse las mismas deficiencias, pero su solución es aplazada de nuevo. En la reunión convocada por AEDEMO para analizar la situación suscitada por las diferencias entre encuestas y resultados reales, se crea una comisión para investigar lo sucedido y emitir un informe, que aún no se ha hecho público.

La preexistencia del objeto representado no es puesta en duda, ni por los medios de comunicación más críticos ni por los institutos de investigación. Sólo falla la utilización del instrumento de medida. La idea inducida por la representación científica es la «verdad». La ciencia se opone a la ideología, de la misma manera que lo objetivo (realidad que se mide) y lo subjetivo: Intervención humana. En términos periodísticos, la máxima del periodismo anglosajón: los hechos son sagrados, los comentarios libres. Sin embargo puede decirse que la representación científica esta cargada ideológicamente -en el sentido de borrar las huellas de su construcción como objeto. Solo el conocimiento erróneo requiere de una explicación, el verdadero surge por sí mismo.

El debate en torno a los sondeos se mueve en un nivel superficial. Se ocupa de la búsqueda de culpables, de la derivación de la responsabilidad y de las justificaciones. Los sondeos no son puestos en duda, y los argumentos del debate arropan, más que ponen en duda, el núcleo fundamental del objeto. Todos los actores del debate -medios de comunicación, políticos y empresas de sondeosestán especialmente interesados en sostener esta representación científica de la realidad social. En la publicación de los sondeos se adopta implícitamente el modelo realista de las ciencias de la naturaleza del siglo XIX, omitiendo las controversias y negociaciones que se dan en el proceso de la producción social del conocimiento, que desde posturas más reflexivas, asume la actual sociología de la ciencia.

\section{IMÁGENES DE LOS SONDEOS EN PRENSA: UNA DUALIDAD DISCURSIVA AL SERVICIO DE LA DEMOCRACIA}

Como ya hemos visto, los sondeos y encuestas circulan a través de los medios de comunicación como discursos que se enfrentan, no siempre ordenadamente, en un mismo espacio, a través del cual son impulsados en forma divulgativa y propagandística para llegar al lector con un efecto persuasivo $\mathrm{e}$ informador.

Las imágenes discursivas de los sondeos se debaten entre la ciencia y la magia, entre la manipulación y la objetividad, entre el afecto y el odio de quienes los utilizan, son imágenes encontradas que van superponiéndose hasta que llega la prueba de fuego: el recuento oficial de los votos. Esta dualidad sitúa a los sondeos como un instrumento eficaz, estrechamente relacionado con el discurso pluralista, consensual e igualitario característico del discurso de la democracia, frente a lo arcaico, a lo no científico y a la legitimación unipersonal de los gobiernos autocráticos, cuya herramienta fundamental es la fuerza. 
Desde una visión global, se podrían distinguir dos tipos de discursos, aquellos que legitiman el uso y la fiabilidad de la utilización de los sondeos como herramienta para obtener el pulso de la opinión pública y prever el futuro, y aquellos que niegan su validez bién por las técnicas empleadas, o por la fragilidad de los resultados, al ser un hecho social, fácilmente cambiante.

\subsection{Los sondeos: herramienta científica por excelencia}

Los sondeos inundan las páginas de los periódicos vertiendo sus resultados, los medios de comunicación encargan sus propias encuestas, los partidos políticos también tienen las suyas (de empresas privadas o instituciones públicas) incluso antes de que comience oficialmente la campaña electoral... los titulares no muestran los fríos datos obtenidos, sino las consecuencias que de ellos se obtienen avaladas por las empresas importantes en el sector, incluso hay unión de medios (tv, radio y periódico) demostrando la sofisticación y la importancia del trabajo encomendado («esfuerzo multimedia»), se reflejan los trabajos de campo, con el número de entrevistas realizadas, (cuanto mayor es la muestra más representativa y menor margen de error) con un lenguaje científico, cargado de objetividad y avalado por el número, que es preciso, exacto y que no da margen para la interpretación subjetiva..., los verbos predican del sujeto... los sondeos «demuestran, reflejan, indican...», e indican factualidad «el PP gana por ...», previsiones como hechos consumados, como realidades anticipadas, medidas de la opinión pública en un momento determinado, aplicando un método objetivo que nos aleja de aquella sociología que emitía juicios de valor y que se aleja del determinismo absoluto para refugiarse en el determinismo estadístico.

Se desarrollan así los sondeos en un espacio virtual (ayudados por la sofisticación tecnológica) en el que se ensaya el acto real del día de las elecciones: es una fotografía, un retrato, una holografía con vida propia que los convierte en actor-sujeto del escenario electoral. Las encuestas son medida de acción para los políticos, guías de actuación que adelantan el futuro, consiguiendo una comunión de voces que predican al unísono la validez absoluta, casi con precisión matemática, de los resultados.

\subsection{Un segundo uso: la «prospección» de la privacidad}

Los sondeos parecen recoger no solo la intención de voto de los encuestados, sino que a la vez nos descubren las creencias ideológicas, los deseos y las ilusiones de los sujetos en el ámbito político, (convertidos en electores, votantes, españoles con alguna operación simple de extrapolación) aunque ellos no lo sepan. La herramienta es tan precisa y tan fiable que si falla es por no haber sabido desentrañar «el voto oculto", las tendencias de los indecisos, incluso parece que son los votantes los que fallan, y no las técnicas... 


\section{3. «La pared de papel»}

Se descubre también que los sondeos sirven para que los ciudadanos expresen y ejerzan la justicia «lapidariamente» y a nivel individualizado. A través de ellos el electorado castiga «duramente» o premia las actuaciones del gobierno y las promesas de los aspirantes, sirve de confesión escrita (algunos votantes no participan por «verguienza»), de escondrijo (no muestran su verdadera intención) de resistencias (enfrentándose a lo público con la ocultación). Tarea difícil es la de los expertos cuya misión es «desentrañar el voto oculto» y de averiguar la verdadera intención de voto.

\subsection{Las encuestas como ejercicio de libertad en democracia}

Se encuentran frecuentemente retazos de discurso en los que sondeos, participación y democracia son un solo cuerpo. El poder se legitima no a través de la fuerza sino a través del consenso, interesa la opinión de la mayoría (y no de la totalidad, dando cabida así a la pluralidad y a las voces discordantes, la soberanía del pueblo («la calle ha hablado») el ejercicio de libertad y autodeterminación que nos aleja del orden divino de períodos históricos anteriores, abandonando la fuerza y la violencia legitimadora en otras épocas para dar paso a una batalla a la luz pública, en un enfrentamiento dialéctico angustioso en el que las lanzas se convierten en lenguas que esgrimen sus posiciones a través de los medios de comunicación, y las fuerzas se miden a través de la oratoria y los audiovisuales... una guerra moderna en la que las armas secretas son los sondeos que aparecen a menudo como enemigos participantes de la contienda «venceremos a las encuestas»...

\section{LOS GURÚES Y SUS ARCANOS}

Paralelamente al discurso legitimador circula uno de descrédito (complementariedad de contrarios), que resalta lo verdadero, quizás por la desconfianza anticipada o comprobada, quizás porque «nos están tomando el pelo»... los sondeos y los métodos se presentan como un arte, más que como ciencia, un arte adivinatorio en el que los entrevistados lanzan sus apuestas, un oráculo que predice el futuro, alejándonos así del rigor científico que demuestra su eficacia y validez una vez conocidos los resultados, al que se le reprochará su oscurantismo a la hora de averiguar porqué han fallado en sus predicciones los augures de la opinión pública. Aun así su utilidad está en su carácter lúdico «divierten al electorado» y es una forma aglutinar individualidades «la gente quiere saber lo que opina la gente»...

\section{Se discuten los métodos, se discuten las técnicas}

Una vez aceptado unánimemente la capacidad del objeto para ser estudiado, los errores pueden ser debidos a las técnicas utilizadas, a las manipulaciones 
indebidas por parte de los expertos, a la porosidad de los hechos sociales o a la calidad y envergadura comercial de las empresas encargadas de los trabajos de investigación, aun se confía en los sondeos, pero los hay buenos y los hay malos, falsos y verdaderos... terminan siendo desprestigiados y calificados de seudocientíficos, los expertos son aquí manipuladores, estafadores en una transacción comercial con un espléndido beneficio que muestra «la generosidad» de los clientes, un intercambio en el libre mercado que no reúne garantías, y por el que se ha de pagar un «justo precio»... el descrédito y la ruptura mercantil.

\section{La subjetividad en la manipulación}

A veces la opinión pública es rígida, decidida, sabe lo que quiere y lo expresa firmemente con antelación, algunos condicionantes pueden influir, pero no de forma importante para variar los resultados, otras veces la opinión pública es frágil, delicada y sensible y puede ser fácilmente influenciada por la anticipación de resultados, las encuestas tienen un efecto perverso, informando con antelación del final del acertijo, se es consciente de la influencia de los sondeos en los individuos, sin saber claramente en que sentido, y de la amplificación de su impacto a través de los medios de comunicación.., aun así se utilizan y se interpretan a favor de intereses particulares, de ahí que no coincidan, y que estén cargadas de una subjetividad desde sus inicios (formulación de las preguntas del cuestionario) hasta su interpretación final a favor o en contra, según convenga.

\section{La relación afectiva sujetos-sondeos}

Para poder situar estos retazos discursivos, no podríamos finalizar sin referirnos a la relación afectiva que se establece en la retórica de este espacio electoral entre los sondeos y sus clientes... en un principio el sondeo informa, da luz, da seguridad de acción, se confía plenamente en sus resultados, casi con pasión, con fe ciega que queda desmoronada al conocer «la gran mentira», el fallo, errores (o desviaciones, según los expertos) que se comprueban en el momento en que comienza el recuento de votos. La candidez de los políticos, sobre todos los que salían victoriosos en los resultados, queda demostrada y hecha pública, sin pudor, jurando venganza, pero con un hilo de esperanza, cuando se indica que «se volverá a caer en la misma piedra», lo que ya ocurrió en anteriores elecciones, confiando desde una amnesia colectiva en el rigor y la fiabilidad de unos sondeos que en realidad tratan de medir algo social, intangible, y por ello, difícilmente medible.

\section{BIBLIOGRAFÍA}

AEDEMO (1986) (Asociación Española de Estudios de Mercado, Marketing y Opinión)ESOMAR (European Society for Opinion and Research Association). Código Internacional de prácticas en materia de publicación de resultados de sondeos de opinión y normas para su interpretación, Barcelona, AEDEMO. 
AEDEMO-ESOMAR (1989): Cómo interpretar y publicar los resultados de las encuestas. Guía para los profesionales de los medios de comunicación. Barcelona, AEDEMO.

ARANGO, Joaquín (1996): «¿Han fracasado las encuestas preelectorales?», en Especial Elecciones, n. ${ }^{\circ} 42$, Madrid, Ed. AEDEMO.

COTARELO, Ramón (1996): «Elecciones del 6 de junio. ¿Qué pasó?», en Especial Elecciones, n. ${ }^{\circ}$ 42, Ed. Asociación Española de Estudios de Mercado Marketing y Opinión. Barcelona, AEDEMO.

Grossi, Giorgio (1985): «La comunicación política moderna: entre partidos de masa y mass media", en Sociología de la comunicación de masas, M. de Moragas (Ed.), Barcelona, Gustavo Gili, S.A.

IBÁÑEZ, Jesús (1997): «Encuestas electorales, arma política», «un sujetador para sujetar sujetos» y «Las encuestas acertaron», en: A contracorriente, Madrid, Ed. Fundamentos.

IMBERT, Gerard (1986): «El discurso de la representación» en: El País o la referencia dominante, Barcelona, Ed. Mitre.

LE GUERN, M. (1990): La metáfora y la metonimia, Madrid, Ed. Cátedra.

ORTí, Alfonso (1996): «La fuerza del deseo electoral. Historia de un espejismo colectivo... que las encuestas reflejaron correctamente», en Especial Elecciones, n. ${ }^{\circ} 42$, Madrid, Ed. AEDEMO.

VAN DIJK, T. (1990): La noticia como discurso. Comprensión estructura y producción de la información., Barcelona, Ed. Paidós.

- (1993): «El estudio interdisciplinario de las noticias y el discurso», en Metodologías cualitativas de investigación en comunicación de masas, Jensen K.B./Jankowski, N.W. Barcelona, Eds. Bosch.

VIDAL BENEYTO, José (1986): «El espacio público de referencia dominante», en: El País o la referencia dominante, Imbert, G. Vidal Beneyto, J. Barcelona, Ed. Mirte.

WOOLGAR, Steve (1991): Ciencia: abriendo la caja negra, Barcelona, Ed. Anthropos.

\section{RESUMEN}

La publicación en la prensa de los datos de las encuestas y los argumentos a favor o en contra, después del «fallo» de las predicciones, reflejan las diferencias en los discursos de políticos, medios de comunicación e institutos de investigación.

El debate sobre las encuestas electorales, permiten conocer el universo simbólico construido alrededor de los sondeos, mediante el análisis de las figuras retóricas y las categorías empleadas.

Las diferencias substantivas entre los pronósticos de los sondeos y el resultado de las elecciones, producen la ruptura del consenso acerca te la encuesta como objeto científico, haciendo explícitos los aspectos subjetivos de la objetivación de la intención de voto en la medida.

\section{ABSTRACT}

The press release of statistical data after the "breakdown» of forecasts, and arguments in favour or against statistics, show the differences from political speeches to those of the media and the research institutions. 
ANÁLISIS DEL DISCURSO DE LA PRENSA SOBRE LAS ENCUESTAS ELECTORALES..

Debates about voting polls allow us to know the token universe built around polls, through the analysis of rhetorical figures and conceptual categories.

The substantive differences from poll forecasts to the election results give rise to the breaking of the consensus concerning polls as a scientific object, pointing out the subjective aspects of measuring the voting intention. 